\title{
Diferentes substratos na propagação por estaquia de assa-peixe (Vernonia polyanthes Less)
}

\author{
GOMES, J.A.O. ${ }^{1 *}$; TEIXEIRA, D.A. ${ }^{1}$; MARQUES, A.P.S. ${ }^{1}$; BONFIM, F.P.G. ${ }^{1}$ \\ ${ }^{1}$ UNESP, Faculdade de Ciências Agronômicas, Departamento de Horticultura, Fazenda Lageado, Portaria I: Rua \\ José Barbosa de Barros, $n^{\circ}$ 1780, Cx. Postal 237, CEP 18.610-307-Botucatu, SP. *Autor para correspondência: \\ jordanyufmg@yahoo.com.br
}

\begin{abstract}
RESUMO: O presente trabalho teve como objetivo avaliar a propagação vegetativa do assapeixe Vernonia polyanthes Less utilizando estacas apicais e diferentes substratos. O experimento foi conduzido em condições de casa de vegetação com irrigação controlada na Faculdade de Ciências Agronômicas da UNESP campus Botucatu- SP. O delineamento experimental utilizado foi o inteiramente casualizado, com sete tratamentos (Solo de textura argilosa; $50 \%$ Solo de textura argilosa $+50 \%$ Húmus; Solo de textura média; $50 \%$ Solo de textura média + $50 \%$ Húmus; Solo de textura arenosa; $50 \%$ Solo de textura arenosa $+50 \%$ Húmus; Húmus) e quatro repetições, sendo 10 estacas por repetição. As características avaliadas foram: comprimento da maior raiz, comprimento da parte aérea, número de brotações, porcentagem de enraizamento, volume radicular, nota para qualidade das estacas e massa seca da parte aérea e das raízes. Os dados foram submetidos à análise de variância pelo teste $\mathrm{F}$ e as médias comparadas pelo teste de Scott \& Knott a $5 \%$ de probabilidade. Para a análise estatística, utilizou-se o programa SISVAR ®. A partir da análise, observou-se efeito altamente significativo dos tratamentos utilizados para todas as variáveis analisadas, com exceção da massa seca da parte aérea, que não apresentou diferença significativa. Para obtenção de melhor enraizamento da espécie em questão, o recomendado é a utilização do substrato: solo de textura argilosa ou média, acrescido de húmus na proporção de 1:1.
\end{abstract}

Palavras- chave: cerrado, planta medicinal, propagação vegetativa, húmus.

\begin{abstract}
ABSTRAT: Different substrates on cutting propagation of assa-peixe (Vernonia polyanthes Less). The current study aimed to evaluate the vegetative propagation of assa-peixe using apical cuttings and different substrates. The trial was conducted under greenhouse conditions with controlled irrigation, in the Faculdade de Ciências Agronômicas of UNESP in Botucatu- SP campus. The experimental design was completely randomized, with seven treatments and four replications, with 10 cuttings per replicate. The characteristics were: longest root length, shoot length, number of shoots, rooting percentage, root volume, score of quality of cuttings and dry mass of shoots and roots. The data were subjected to analysis of variance by $\mathrm{F}$ test and the averages were compared by the Scott Knott test at $5 \%$ probability. For statistical analysis, we used the SISVAR ®. From the analysis, we observed highly relevant effect of the treatments used for all variables, with the exception of the dry weight of shoots, which did not present significant difference. In order to obtain a better rooting of the species concerned, the recommended method would be to use substrates such as clayey soil or medium plus humus in the ratio 1:1.
\end{abstract}

Keywords: cerrado, medicinal plant, vegetative propagation, humus.

\section{INTRODUÇÃO}

Vernomia polyanthes Less., popularmente conhecida como assa-peixe, assa-peixe branco, estaca-sangue, tramanhém, mata-pasto, cambaráguassu, cambará-do-branco, erva-preá e enxuga é uma planta nativa arbustiva, comum nos cerrados de São Paulo, Minas Gerais e Goiás (Alzugaray \& Alzugaray, 1984). Suas folhas são utilizadas no tratamento de afecções do aparelho respiratório, problemas renais, fraturas, indicada também como tônica, emenagoga e diurética (Grande et al., 
1989; Lorenzi \& Matos, 2008). Em 2009 foi incluída na lista do RENISUS, que tem por finalidade o desenvolvimento de toda cadeia produtiva, desde a regulamentação, cultivo/manejo, produção, comercialização até a dispensação de plantas medicinais e fitoterápicos (Nascimento Junior, 2009).

A estaquia é a técnica de propagação vegetativa mais rápida e de mais fácil execução, sendo utilizada nas espécies que apresentam maior facilidade para a formação de raízes adventícias. A técnica consiste na multiplicação de plantas usando segmentos caulinares ou radiculares providos de gemas meristemáticas com capacidade para emitir raízes adventícias, comumente denominados estacas (Hartmann et al., 2008). Este método possui a vantagem de garantir a seleção de genótipos superiores, maior produção de mudas em menor espaço de tempo (Neves et al., 2006), além de permitir a escolha de genótipos com maior produção de compostos especializados.

Substratos apresentam papel fundamental no desenvolvimento das muda e devem possuir baixa densidade, boa capacidade de absorção e retenção de água, boa aeração e drenagem, além de estar isento de pragas, doenças e substâncias tóxicas. Normalmente, todas estas características não são encontradas em um único componente, o que leva a utilização de misturas de materiais para a obtenção de um melhor substrato (Kämpf, 2000; Wendling et al., 2002). O material deve fornecer à estaca bom suprimento de água e ao mesmo tempo boa aeração (Bitencourt et al., 2010). É importante que os insumos a serem utilizados na composição dos substratos sejam de fácil disponibilidade na região, o que favorece a sua aquisição (ArrigoniBlank et al., 2013).

Várias são os materiais que podem ser utilizados na composição do substrato para produção de mudas, como casca de arroz carbonizada; serragem; turfa; vermiculita; composto orgânico; esterco bovino; moinha de carvão; material de subsolo; bagaço de cana; acícula de pinus; areia lavada, além das diversas misturas entre estes componentes (Gomes, 1991; Paiva et al.,1996). Quando se trata de espécies nativas, com pouco conhecimento agronômico, é necessária a identificação dos fatores que afetam a germinação ou propagação vegetativa desse individuo (Blank et al., 2003).

Pesquisas sobre a propagação de espécies medicinais são de elevada importância, uma vez que servem de base para a domesticação e o sucesso do cultivo dessas plantas. No entanto, trabalhos nessa área ainda são escassos, como no caso do assa-peixe que necessita de informações quanto à recomendação de substratos para produção de mudas. Dessa maneira, o trabalho teve como objetivo avaliar a qualidade do enraizamento de estacas de assa-peixe (Vernonia polyanthes Less) em diferentes substratos.

\section{MATERIAL E MÉTODOS}

O experimento foi conduzido em condições de casa de vegetação, com irrigação controlada, duas vezes ao dia, no período de abril a junho de 2014. Para a caracterização química substratos foram realizadas análises quanto aos parâmetros de $\mathrm{pH}$, matéria orgânica $(\mathrm{MO})$, fósforo $(\mathrm{P})$, acidez potencial $(\mathrm{H}+\mathrm{Al})$, potássio $(\mathrm{K})$, cálcio $(\mathrm{Ca})$, magnésio $(\mathrm{Mg})$, soma de bases (SB), capacidade de troca de cátions (CTC) e saturação de bases (V\%), no Laboratório de Solos da Unesp-Botucatu.

$\mathrm{Na}$ obtenção do material vegetal, foram coletadas estacas apicais herbáceas com 15 $\mathrm{cm}$ de comprimento de plantas matrizes de $V$. polyanthes, localizadas na Faculdade de Ciências Agronômicas da Universidade Estadual Paulista, na cidade de Botucatu, em São Paulo (SP) e depositada no Herbário Irina Delanova Gemtchujnicov, Universidade Estadual Paulista, Botucatu-SP, sob registro BOTU 25797-assa peixe. As folhas medianas e basais foram removidas, preservando-se somente um par de folhas apicais, cortadas de forma a dispor apenas metade de sua área foliar, e na base da estaca foi feito corte em bizel. Em seguida, as estacas foram transferidas para jardineiras contendo os sete diferentes tipos de substratos.

Com intuito de avaliar substratos alternativos os tratamentos (substratos) avaliados foram: (T1)Húmus; (T2)- Solo de textura arenosa; (T3) - 50\% Solo de textura arenosa $+50 \%$ Húmus; (T4)- $50 \%$ Solo de textura argiloso $+50 \%$ Húmus; (T5)- Solo de textura argiloso; (T6)- $50 \%$ Solo de textura médio + $50 \%$ Húmus; (T7)- Solo de textura média.

O delineamento experimental utilizado foi o inteiramente casualizado, com sete tratamentos e quatro repetições, onde cada parcela composta por conteve 10 estacas. Após 60 dias do plantio foram avaliados: o comprimento da maior raiz (CR), comprimento da parte aérea (CPA), o número de brotações (NB), a porcentagem de enraizamento (PE), volume radicular (VOL), avaliação visual do enraizamento (NT) e a massa seca das partes aérea (MSPA) e das raízes (MSR). Utilizou-se um paquímetro digital com precisão de centésimo de milímetro para a medição das raízes e uma balança digital analítica com precisão de milésimo de grama para a determinação das massas. Na avaliação visual do enraizamento de cada estaca, foram atribuídas notas de 0 (níveis de enraizamento inferiores) a 5 (níveis de enraizamento superiores) por dois avaliadores, sendo considerada a média aritmética

Rev. Bras. PI. Med., Campinas, v.17, n.4, supl. III, p.1177-1181, 2015. 
dessas notas como nota final da avaliação.

Para a análise estatística (SISVAR ${ }^{\circledR}$ versão 5.3 ), os dados foram submetidos à análise de variância pelo teste $\mathrm{F}$ e as médias foram comparadas pelo teste Scott \& Knott, a 5\% de probabilidade de erro para ambos os testes. Os dados de número de brotações, números de estacas vivas e da avaliação visual do enraizamento foram transformados em $\sqrt{ } x_{+} 0,5$ e a porcentagem de enraizamento foi transformada em arco-seno $\sqrt{ } \mathrm{x} / 100$, uma vez que tais dados não apresentaram variâncias homogêneas pelo teste de Hartley. Para os dados referentes à contagem e atribuição de notas, por seguirem a distribuição de Poisson, utilizou-se a transformação de raiz quadrada, já para aqueles dados referentes às porcentagens, por seguirem a distribuição binomial, procedeu-se à transformação angular (Banzatto \& Kronka, 2006).

\section{RESULTADOS E DISCUSSÃO}

Os diferentes tipos de solo, acrescidos de húmus apresentaram mudanças nas características químicas.

Observa-se aumento da saturação por base ( $\mathrm{V} \%)$ com a adição desta fonte de matéria orgânica, variando o pH dos substratos entre 4 e 6,2. (Tabela 1). Na espécie Mikania glomerata Spreng., nota-se a formação de raízes independente da adição de matéria orgânica (vermicomposto) (Vidal et al., 2006). Verifica-se a necessidade de fazer a mistura de componentes e selecionar a melhor combinação para encontrar o substrato que atenda as características físicas e nutricionais exigidas pelas mudas (Paulus et al. 2011).

Nos tratamentos utilizados, observa-se efeito altamente significativo $(p>0,01)$ para todas as variáveis analisadas, com exceção da massa seca da parte aérea. Os substratos, solo de textura argilosa + húmus e solo de textura média + húmus alcançaram maiores médias para todas as características avaliadas (Tabela 2). Sendo que para comprimento radicular e comprimento da parte aérea, os substratos, solo de textura arenosa + húmus e solo de textura média também se destacaram por apresentar maiores médias, embora não diferiram estatisticamente dos anteriores.

A porcentagem de enraizamento e o comprimento da raiz dos melhores tratamentos (4 e 6), quando comparados ao uso do húmus puro, foram de oito e cinco vezes maiores, respectivamente. $O$ substrato adequado para 0 melhor enraizamento deve ser suficientemente poroso, a fim de permitir trocas gasosas eficientes, visto que a maior disponibilidade de oxigênio na base das estacas favorece a atividade celular durante o processo de formação de calos e posterior emissão de raízes (Hartmann et al., 2002).

Para a característica volume das raízes, os melhores tratamentos foram os solos acrescido com húmus e para massa seca da raiz, além dos tratamentos já mencionados anteriormente, o tratamento solo de textura média se destacou e diferiu dos demais. $\mathrm{O}$ húmus é indicado para uso como condicionador de substrato para estaquia de carqueja por incrementar o crescimento da parte aérea, além do crescimento radicular (Carvalho et al., 2007), o que também ocorreu no presente trabalho.

Os substratos húmus e areia obtiveram o pior desempenho para todas as características referentes ao enraizamento. A areia possui atributos, como partículas minerais inertes $\mathrm{e}$ baixa capacidade de retenção de água (Wendling, 2002), além de possuir baixa saturação por (Tabela 1). Sendo assim, é notada características totalmente opostas nos tratamentos que utilizaram húmus puro, o que pode justificar o baixo desempenho de estacas apicais de assa-peixe quando submetidas aos dois substratos. Biasi \& De Bona (2000) concluíram que para propagação de carqueja por estaquia, os substratos não influenciaram o enraizamento das mesmas. Assim como para o

TABELA 1. Análise química dos substratos utilizados no experimento

\begin{tabular}{lllllllllll}
\hline \multirow{2}{*}{ Solo } & $\mathrm{pH}$ & $\mathrm{M} . \mathrm{O}$. & $\mathrm{P}_{\text {resina }}$ & $\mathrm{H}+\mathrm{Al}$ & $\mathrm{K}$ & $\mathrm{Ca}$ & $\mathrm{Mg}$ & $\mathrm{SB}$ & $\mathrm{CTC}$ & $\mathrm{V} \%$ \\
\cline { 2 - 9 } & $\mathrm{CaCl}_{2}$ & $\mathrm{~g} / \mathrm{dm}^{3}$ & $\mathrm{mg} / \mathrm{dm}^{3}$ & $-----------\mathrm{mmol}_{\mathrm{c}} / \mathrm{dm}^{3}$ & ------- & & & \\
\hline Húmus & 6,2 & 64 & 247 & 21 & 9,4 & 123 & 36 & 169 & 189 & 89 \\
Médio & 4,0 & 16 & 2 & 64 & 0,5 & 3 & 1 & 4 & 69 & 6 \\
Arenoso & 4,8 & 5 & 12 & 13 & 0,8 & 15 & 1 & 17 & 30 & 56 \\
Argiloso & 5,7 & 30 & 27 & 30 & 2,1 & 65 & 25 & 92 & 122 & 76 \\
Médio + Húmus & 5,3 & 51 & 219 & 23 & 9,5 & 145 & 33 & 187 & 210 & 89 \\
Arenoso + Húmus & 6,2 & 32 & 227 & 17 & 9,8 & 116 & 27 & 153 & 170 & 90 \\
Argiloso + Húmus & 6,0 & 56 & 236 & 20 & 10,1 & 201 & 36 & 247 & 267 & 92 \\
\hline
\end{tabular}

Rev. Bras. PI. Med., Campinas, v.17, n.4, supl. III, p.1177-1181, 2015. 
TABELA 2. Valores médios da porcentagem de enraizamento (PER), comprimento da raiz (CR) e comprimento da parte aérea (CPA) em centímetros, número de brotos (NB), volume da raiz (VOL) em centímetros cúbicos, estacas vivas (ESV), massa seca da raiz (MSR), massa seca da parte aérea (MSPA), avaliação visual da raiz (NT) de assa-peixe submetidas a diferentes substratos.

\begin{tabular}{llllllll}
\hline Tratamentos & PER & CR & CPA & NB & VOL & MSR & NT \\
\hline Húmus & Oc & $1,00 \mathbf{c}$ & $1,48 \mathbf{b}$ & $1,00 \mathbf{b}$ & $1,00 \mathbf{b}$ & $1,04 \mathbf{b}$ & $0,71 \mathbf{c}$ \\
Arenoso & $5 \mathbf{c}$ & $2,30 \mathbf{b}$ & $2,01 \mathbf{b}$ & $1,00 \mathbf{b}$ & $1,02 \mathbf{b}$ & $1,05 \mathbf{b}$ & $1,01 \mathbf{c}$ \\
Arenoso+Húmus & $25 \mathbf{b}$ & $4,43 \mathbf{a}$ & $3,28 \mathbf{a}$ & $1,00 \mathbf{b}$ & $1,34 \mathbf{a}$ & $1,08 \mathbf{b}$ & $1,43 \mathbf{b}$ \\
Argiloso+Húmus & $67 \mathbf{a}$ & $4,35 \mathbf{a}$ & $3,63 \mathbf{a}$ & $2,00 \mathbf{a}$ & $1,52 \mathbf{a}$ & $1,22 \mathbf{a}$ & $2,08 \mathbf{a}$ \\
Argiloso & $15 \mathbf{c}$ & $2,80 \mathbf{b}$ & $2,33 \mathbf{b}$ & $1,25 \mathbf{b}$ & $1,19 \mathbf{b}$ & $1,09 \mathbf{b}$ & $1,10 \mathbf{c}$ \\
Médio+Húmus & $68 \mathbf{a}$ & $4,88 \mathbf{a}$ & $3,82 \mathbf{a}$ & $2,53 \mathbf{a}$ & $1,44 \mathbf{a}$ & $1,26 \mathbf{a}$ & $2,17 \mathbf{a}$ \\
Médio & $38 \mathbf{b}$ & $4,49 \mathbf{a}$ & $3,55 \mathbf{a}$ & $1,35 \mathbf{b}$ & $1,23 \mathbf{b}$ & $1,15 \mathbf{a}$ & $1,36 \mathbf{b}$ \\
\hline
\end{tabular}

As médias seguidas da mesma letra na coluna não se diferem estatisticamente pelo teste Scott- Knott a $1 \%$ de probabilidade.

atroveran (Ocimum selloi), onde os substratos casca de arroz, substrato comercial e areia não influenciaram o enraizamento (Costa et al., 2007). Outras espécies que não apresentaram diferenças significativas para os substratos utilizados foram, Ocimum gratissimum (Ehlert et al., 2004), Lippia alba (Biasi \& Costa, 2003), Baccharis trimera (De Bona et al., 2005) e Ageratum conyzoides (Momenté et al., 2002). Resultados estes não são vistos na espécie estudada neste trabalho.

O solo argiloso é um substrato com alta densidade e pouca porosidade (Kämpf, 2000), que não são características desejáveis para o enraizamento de estacas. Na estaquia semilenhosa de guaco, o substrato solo puro foi inferior à casca de arroz carbonizada e areia em relação ao desenvolvimento do sistema radicular (Lima, 2001). Na espécie Syzygium malaccensis a propagação por estaquia foi favorecida pela areia (Lima et al., 2007). Estes resultados divergem dos encontrados para $V$. polyanthes, onde areia obteve médias inferiores estatisticamente para as características avaliadas. Notadamente, a adição do húmus proporcionou um incremento de nutrientes ao substrato, quando comparado às diferentes classes de solos, o que proporcionou melhor desenvolvimento da parte aérea e raiz.

Mesmo que o substrato comercial Plantmax ${ }^{\circledR}$ seja recomendado para produção de mudas de menta por estaquia, a mistura casca de arroz + solo ou areia se mostraram apropriados para produção, pois atendem as exigências da cultura, além de possuírem baixo custo (subproduto) e serem facilmente adquiridos (Paulus \& Paulus, 2007). A mistura de dois materiais permite atingir níveis intermediários de retenção de água, de aeração e de disponibilidade de água nos substratos, favorecendo o enraizamento de estacas (Souza et al., 2006).

\section{CONCLUSÃO}

Os dados obtidos indicam que entre os substratos avaliados, para alcançar melhores características de enraizamento e produzir mudas de qualidade, é recomendado o uso de solo de textura argilosa ou média acrescido de húmus na proporção de 1:1.

\section{REFERÊNCIAS}

ALZUGARAY, D; AZUNGARAY, C. Flora Brasileira Primeira Enciclopédia de Plantas do Brasil. v.1, p.65-66, 1984

ARRIGONI-BLANK, M. F. et al. Produção de mudas de vetiver (Chrysopogon zizanioides (L.) Roberty) com uso de diferentes substratos. Biosciense Journal v. 29, n. 3, p. 597-604, 2013.

BANZATTO, D.A.; KRONKA, S.N. Experimentação agrícola. Jaboticabal: FUNEP, 2006. 237p.

BIASI, L.A.; DE BONA, C.M. Propagação de carqueja (Baccharis trimera (Less.) A.P. de Candolle) por meio de estaquia. Revista Brasileira de Plantas Medicinais, v. 2, n. 2, p. 37-43, 2000.

BIASI, L.A.; COSTA, G. Propagação vegetativa de Lippia alba. Ciência Rural, v.33, n.3, p.455-459, 2003.

BITENCOURT, J. et al. Estaquia de Ginkgo biloba L. utilizando três substratos. Revista Brasileira de Plantas Medicinais, v. 12, n. 2, p. 135-140, 2010.

BLANK, A.F. et al. Produção de mudas de sambacaitá (Hyptis pectinata L. Poit) em função de recipientes, composição de substratos e calcário. Horticultura Brasileira, v.21, n.1, p.1-4, 2003.

DE BONA, C.M. et al. Estaquia de três espécies de Baccharis. Ciência Rural, v.35, n.1, p.223-226, 2005.

CARVALHO, R.I.N et al. Enraizamento de estacas de carqueja em função de diferentes substratos e posição no ramo em plantas masculinas e femininas. Scientia Agraria, v.8, n.3, p.269-274. 2007.

COSTA, L.C.B. et al. Comprimento da estaca e tipo de substrato na propagação vegetativa de atroveran. Ciência Rural, v.37, n.4. 2007.

EHLERT, P.A.D. et al. Propagação vegetativa da alfavacacravo utilizando diferentes tipos de estacas e substratos.

Rev. Bras. PI. Med., Campinas, v.17, n.4, supl. III, p.1177-1181, 2015. 
Horticultura Brasileira, v.22, n1, p. 10-13, 2004

GOMES, J. M. et al. Efeito de diferentes substratos na produção de mudas de Eucalyptus grandis W. Hill ex Maiden, em "Win-Strip". Revista Árvore, v. 15, n. 1, p. 35-42,1991.

GRANDE, T.S.M. et al. Botanical Survey on Medicinal Plants Used by the Population of the State of the Minas Gerais. Brasil. Simpósio de Química e Farmacologia de Produtos Naturais. 1989.

HARTMANN, H.T. et al. Plant propagation: principles and pratices. 7. ed. New Jersey: Prentice-Hall, 2002. 880 p.

HARTMANN HT. et al. Plant propagation: principles and practices. New Jersey: Prentice-Hall, 2008. 770p.

KÄMPF, A.N. Produção comercial de plantas ornamentais. Guaíba: Agropecuária. 2000. 254p.

LIMA, N.P. Estaquia semilenhosa e comparação de metabólitos secundários em Mikania glomerata Sprengel e Mikania laevigata Schultz Bip ex Baker. 2001. 85f. Dissertação (Mestrado em Agronomia) Curso de Pós-graduação em Agronomia, UFPR.

LIMA, Y.O.U. Tipos de estacas e substratos no enraizamento de jambolão. Scientia Agraria, v.8, n.1, 2007.

LORENZI, H.; MATOS, F.J.A. Plantas medicinais do Brasil. Nativas e Exóticas. Nova Odessa: Instituto Plantarum, 2008. 512 p.

MOMENTÉ, V.G. et al. Propagação vegetativa por estaquia de mentrasto em diferentes substratos. Revista Ciência Agronômica, v.33, n.2, p.5-12, 2002.
NEVES, T. S.; et al., Enraizamento de corticeira-da-serra em função do tipo de estaca e variações sazonais. Pesquisa Agropecuária Brasileira, Brasília, v. 41, n. 12, p. 1699-1705, 2006.

NASCIMENTO JUNIOR, J.N. Programa Nacional de Plantas Medicinais e Fitoterápicos. Disponível em: http://portal.saude.gov.br/portal/arquivos/pdf/daf_sem_ fito.pdf. Brasília: 2009. Acesso em: 15.maio.2014.

PAIVA, H.P.J.M. et al. Propagação vegetativa de eucalipto por estaquia. Informe Agropecuário, v.18, n.185, p. 23-27, 1996.

PAULUS D; PAULUS E. Efeito de substratos agrícolas na produção de mudas de hortelã propagadas por estaquia. Horticultura Brasileira, v.25, p. 594-597, 2007.

PAULUS, D. et al. Avaliação de substratos orgânicos na produção de mudas de hortelã (Mentha gracilis $\mathrm{R}$. Br. e Mentha $x$ villosa Huds.). Revista Brasileira Plantas Medicinnais, v.13, n.1, p.90-97, 2011.

SOUZA, P.V.D. et al. Efeito da composição do substrato no enraizamento de estacas de maracujazeiro azedo. Revista Brasileira Fruticultura, v. 28, n. 2, p. 276279, 2006.

VIDAL L.H.I. et al. Qualidade de mudas de guaco produzidas por estaquia em casca de arroz carbonizada com vermicomposto. Horticultura Brasileira, v.24, p. 26-30, 2006.

WENDLING, I. et al. Substratos, adubação e irrigação na produção de mudas. Viçosa: Aprenda Fácil Editora. $166 p, 2002$.

Rev. Bras. PI. Med., Campinas, v.17, n.4, supl. III, p.1177-1181, 2015. 